\title{
Diffusion dynamics of energy service companies in the residential sector
}

\author{
Andra Blumberga, Dagnija Blumberga, Gatis Žogla, Claudio Rochas, Marika Rošā, Aiga Barisa \\ Institute of Energy Systems and Environment,Riga Technical University \\ Riga, Latvia
}

Received: December 18, 2020. Revised: February 27, 2021. Accepted: March 10, 2021. Published: March $23,2021$.

\begin{abstract}
Energy service contracting (EPC) is one of the private sector instruments to improve end use energy efficiency. The dominant part of EPC projects is implemented in the industrial, governmental and municipal sectors while the residential sector has been less attractive to energy service companies (ESCO). This paper describes the first EPC project implemented in a multi apartment building in Latvia. A combination of this project experience, the system dynamics modelling, and microeconomics theory has been used to develop the system dynamics model to capture the interactions and feedback from the ESCO market for residential building energy efficiency. Three policy tools were tested for use in improving the performance of the system. The purpose of the tests was to facilitate the diffusion (or distribution) of EPC in the residential sector.
\end{abstract}

Keywords - Energy service company, Energy efficiency, System dynamics, Residential buildings, Energy service contracting

\section{INTRODUCTION}

Energy demand is continuously growing worldwide. It is at the core of climate change caused by greenhouse gas (GHG) emissions. The European Commission has adopted the "Energy Roadmap 2050" to reduce $\mathrm{CO}_{2}$ by $80-95 \%$ by 2050 [1]. One of the legislative instruments used at the EU level to achieve end-use energy efficiency is Directive 2006/32/EC on energy end-use efficiency and energy services. Under this Directive, every EU member must reduce end use energy by $9 \%$ by 2016 [2].

One of the energy efficiency policy tools available to the end user is energy service contracting or EPC provided by energy service companies or ESCOs. EPC has a significant effect as a private sector instrument to improve end use energy efficiency. ESCO projects are selffinancing because the investment is paid back from the energy cost reduction. The ESCO business differs from the energy consulting business. The latter assesses exactly which energy efficiency measures should be implemented but is not responsible for achieving the forecasted savings by the measures that it recommended. Energy service contracting may include many different types of activities, e.g., Sorrell [3] suggests describing energy service contracts using three variables: depth, scope and method of finance.

The ESCO concept has been established first in North America at the beginning of 1970s when energy end users faced an energy crisis and were looking for ways to achieve substantial energy cost reductions. Although ESCO is a well-developed branch of business, the available scientific literature on it is not extensive.
However, it provides some insight into the field. Goldman et al. [4] has carried out an empirical analysis of American ESCO market trends and performance. Vine [5] has analysed ESCO activities in 38 countries. Bertoldi et al. $[6,7,8]$ discuss ESCO diffusion in the EU market. In their latest report Marino et al. [9] have concluded that between 2007 and 2010, the European Union ESCO market has grown slowly. The Marino paper also mentions that latest findings reveal that the ESCO market is very complex and turbulent.

The complexity of the energy service contracting market reveals an important need to recognize, understand and manage the dynamic and, in many cases, non-linear interactions influenced by delays between and among the many variables that create both short and long term impacts. System dynamics as a "white box" modelling tool is a very useful device to reveal the structure of the system as well as determine the short and long term behaviour of complex and dynamic systems. The literature on the system dynamics modelling of the ESCO market is very thin. Capelo [10] has approached the ESCO market in Portugal using system dynamics.

In this paper, a case study of the application of ESCO to the residential sector is used to illustrate how system dynamics modelling can address energy efficiency issues through effective national policy making. In Section 2 the background to Latvia's residential sector energy efficiency and a description of ESCO case study is provided. It is followed by Section 3 where the methodological framework is outlined. Sections 4, 5 and 6 provide information on the system dynamics model to be used to support the national energy efficiency policy planning process. Finally, the major findings from model simulations under different policy scenarios are compared and analysed. Discussions and conclusions then follow.

\section{BACKGROUND INFORMATION}

\section{A. Residential sector in Latvia and energy efficiency policy}

The residential sector is currently the largest energy consumer in Latvia, accounting for $38.8 \%$ of overall energy end-use in the country [11]. In 2010, the total housing floor area in Latvia reached 61.1 million $\mathrm{m}^{2}$ [12]. The household sector in Latvia includes multi apartment buildings ( $61.5 \%$ of the total residential building stock) and single-family buildings [12]. Located in the northern part of Europe with cold climate (heating degree days 
above 4000 degree days) the greatest energy consumed in the residential sector is for heating energy with an average annual consumption $180 \mathrm{kWh}$ per $\mathrm{m}^{2}$.

To ensure an implementation of requirements of European Union Directive 2006/32/EC on energy end-use efficiency and energy services, the First National Energy Efficiency Action Plan of Latvia [13] established a goal to reduce energy consumption by $3483 \mathrm{GWh}$ or $9 \%$ by 2016 . The greatest energy savings, that is by $77 \%$ or $2701 \mathrm{GWh}$, are planned for the residential sector.

Although Latvia has a huge residential building energy efficiency potential, only 200 of the more than 30 000 multi apartment buildings are completely renovated. The main causes are rooted in the lack of motivation on the part of apartment owners. The barriers that obstruct the implementation of energy efficiency measures have to be reviewed in the socioeconomic context considering that the residents' motivation is affected not only by rational reasons such as technical issues arising from energy efficiency measures [14] but also by a combination of complex socioeconomic factors such as a lack of awareness and knowledge (that is, know-how), confidence in neighbours and persons implementing energy efficiency measures, various administrative requirements during the implementation process, residents' worries about their solvency and uncertainty regarding their income and ability to undertake more financial obligations as well as other factors.

The most challenging task for the energy efficiency policy is to overcome the lack of collective action, which arises from the ownership structure of multi apartment buildings. Apartments are owned by individual occupants. Implementation of common energy efficiency measures in the building may be performed with the agreement of at least $51 \%$ of apartment owners in the building.

ESCO removes most of the barriers that impede implementation of energy efficiency measures. If an energy service contract is signed with an ESCO, the company guarantees the quality of the construction work. It also assumes all financial risks and absorbs any risk related to administrative barriers.

\section{B. ESCO to increase residential energy efficiency}

Most ESCO projects are implemented in the industrial and governmental/municipal sectors. The residential sector has been less attractive to ESCOs. Multi apartment buildings are among the major energy consumers with high energy savings potential, yet ESCOs have not been active in this market sector. The literature is very thin on the explanation of the reasons. The multi apartment building sector faces similar problems in all East European countries. This results from the historical heritage left from Soviet and East Block times. There are several barriers for ESCOs that are considering entering this market sector. These include collective action problems arising from the ownership structure (every flat in the building is owned by a different owner), general distrust, high administrative barriers, and a perception that construction work will be poor quality.

2009 represented a turning point for residential energy efficiency projects in Latvia and Europe. The energy service company RENESCO implemented energy efficiency project in multi apartment building at Gaujas street 13 in Valmiera. The nine storey building with a total heated area $1914 \mathrm{~m}^{2}$ and 36 apartments was built in 1980 . Its average annual heating and hot water energy consumption is $406 \mathrm{MWh}$ or $214 \mathrm{kWh} / \mathrm{m}^{2}$ per year. The building envelope, heating and hot water supply systems are in poor technical condition and do not meet existing building standards. Water was found to leak through the roof, and much energy was lost through walls and windows. Two thirds of the thermal energy in the hot water loop was lost in the circulation system, and only one third was actually used for water heating. The simulation model showed that the potential energy savings amount to $47 \%$ or $192 \mathrm{MWh}$ per year.

It took six months for RENESCO to persuade apartment owners to sign an energy performance contract for 20 years for the implementation of both energy efficiency and non-energy efficiency measures. Energy efficiency measures taken include insulation of the walls with $10 \mathrm{~cm}$ of mineral wool, the attic with $20 \mathrm{~cm}$ of mineral wool, the basement ceiling with $10 \mathrm{~cm}$ of polystyrene, as well as the installation of new windows and main entrance doors, the reconstruction of the hot water system and the installation of an energy monitoring system in the building. Non-energy efficiency measures such as the renovation of the roof, staircases and balconies, the installation of a new water pump station, and the replacement of the cold water supply system have been implemented to avert serious technical problems and to improve the general appearance of the building. The total investment amounted for both energy efficiency and non-energy efficiency measures to approximately 170,000 EUR.

The financing mechanism of the ESCOs is generally classified as "guaranteed savings" and "shared savings" (Bertoldi et al., 2006). As discussed in Bertoldi et al. [7,8] in countries with developing ESCO markets, the shared savings mechanism is more suitable since it does not require clients to assume investment repayment risk. The adjusted shared savings mechanism was used in the first RENESCO energy performance contract and is illustrated in Fig. 1. The company carries both the performance and the credit risk while the client has no financial risk. The client has no financial obligation other than to pay for the energy consumption to the housing management company as in the baseline, including the actual savings to the ESCO over a specified period of time. This obligation is not considered debt and does not appear on the customer's balance sheet. 


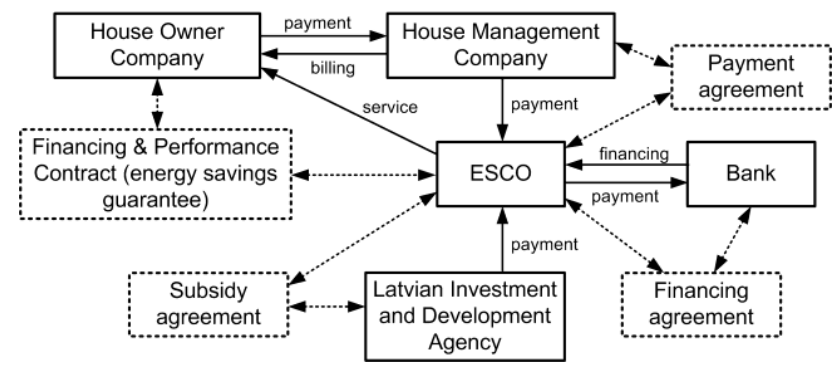

Fig. 1. RENESCO adjusted shared savings mechanism

The monitoring system is installed to follow the energy performance of the building. Hourly data from every flat are collected and analysed to improve energy efficiency even more. Fig. 2. illustrates measured energy consumption before the implementation of energy efficiency measures, the results from the simulation model and real values measured after implementation of energy efficiency measures. The monitoring data show that the average energy savings during first two years are $56.7 \%$. The annual reduction of $\mathrm{CO}_{2}$ emissions is $64.9 \mathrm{t} \mathrm{CO}_{2}$. The total planned energy savings during the duration of the contract are planned to reach $4150 \mathrm{MWh}$ and the corresponding reduction of $\mathrm{CO}_{2}$ emissions $1100 \mathrm{t} \mathrm{CO}_{2}$.

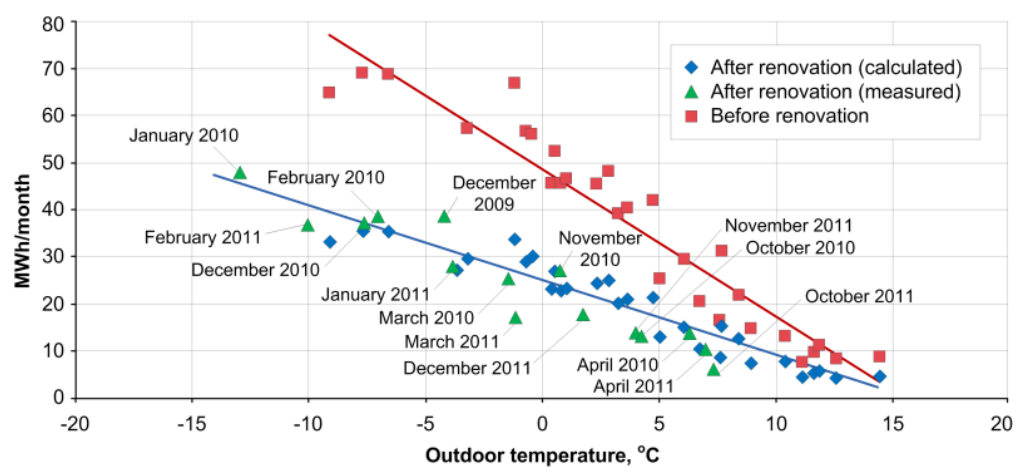

Fig. 2. Heat energy (heating and hot water) consumption in Gaujas 13, Valmiera [15].

The RENESCO project provided additional value both to apartment owners and to society in general. Firstly, RENESCO has proved that an ESCO can remove number of the serious barriers facing energy efficiency projects by assuming either all or most of the technical, administrative, financing, construction quality, financial and credit risks. Secondly, apartment owners highly value the improved safety, indoor comfort and appearance of the building being safeguarded by a long-term energy performance agreement. The last added value is the extended life time of building envelope and technical systems.

Up to March 2012, RENESCO has signed nine more energy performance contracts with other buildings.

\section{METHODOLOGY}

For this study, a combination of system dynamics modelling, microeconomics theory and RENESCO project experience in the residential building energy efficiency sector has been used. The system dynamics model is developed to capture the interactions and feedback of the ESCO market for residential building energy efficiency. This approach is referred to as the "white box" or causal-descriptive modelling tool. For "white box" models, the validity of the internal structure of the model is essential, because the behaviour of the system can be modified by adjusting its structure. This model is developed using the programme Powersim, which is designed to build nonlinear, dynamic systems with delays.
Microeconomics theory is used as analytical framework to address research problems related to human behaviour and energy efficiency and savings [17]. Transaction costs discussed by Sorell [3] are used for ESCO supply model.

The main purpose of the model is to disclose and reproduce the structure of the system how the ESCO market really works in the residential sector and to use it to provide a tool for policy planning.

\section{A SYSTEM DYNAMICS MODEL}

A. Overview of the conceptual model

RENESCO is a typical example of a seller's market where the company is the only market player. The demand for its services depends on the company's sales and marketing capacity. The main reasons behind RENESCO being the only player in the market are a heterogeneous profile of customers (each apartment owner has voting rights), risks based on a complex knowledge of technical, financial, managerial, and legal risks as well as other issues, and he business culture based on short term agreements with low risk.

The conceptual model depicted in Fig. 3. simplifies the ESCO market but includes important relationships and interactions. The model is part of the national residential energy efficiency model described in Blumberga et al. [19]. It illustrates how the major four sectors are related in the common structure to show the diverse nature of the problem. The main sector is the ESCO market where supply and demand 
determines the ESCO diffusion rate in the market. It is closely linked with the financial resources sector that supports the growth of ESCO capacity. The building stock sector includes all residential buildings. The internal dynamics of this stock determines both the
ESCO diffusion in the market and the availability of financial resources. The fourth sector indicates the national energy savings and GHG emissions as result of changes in building stock.

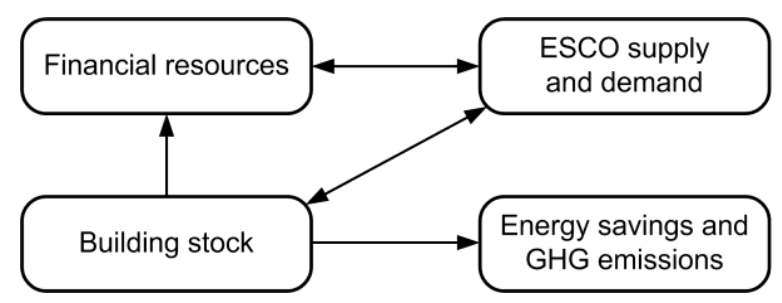

Fig. 3. Conceptual structure of building energy efficiency system dynamics model.

\section{B. Model description}

Fig. 4. depicts the stock and flow diagram of the ESCO supply and demand sub-model. This is the main sub-model. It shows how supply and demand determines the diffusion rate of the ESCO services in the market. The demand is determined by total ESCO costs, the apartment owners' willingness to pay and information perceived by apartment owners about both successful and unsuccessful projects implemented by the ESCO. The ESCO costs comprise internal and external transaction costs, investment costs, energy costs and interest. The ESCO sales capacity depends on the ESCO profit - the higher the profit, the more money can be spent on sales and marketing activities. Energy savings achieved by ESCO increase or decrease depending on the project success rate, which is based on the learning curve of ESCO. Decreased housing maintenance costs as an additional benefit offered by a housing maintenance company are included in the model. The number of votes required (the number of votes needed to decide whether to sign ESCO contract - now $51 \%$ of apartment owners have to agree) is one of the major barriers for ESCOs, and creates very high transaction costs, in particular, sales and marketing costs. This barrier has an impact on inconvenience costs incurred by both apartment owners and the ESCO. The higher the costs, the more financial resources are required for sales and marketing activities. A reduction of housing maintenance costs increases the net benefit of every apartment owner. Because ESCO invests in the general building improvement measures, less housing maintenance is required. This, in turn, increases the willingness of the apartment owners to pay and makes the ESCO more attractive to them. The information delay that is caused by the owners' capability to understand the information determines how net benefits affect their willingness to pay.

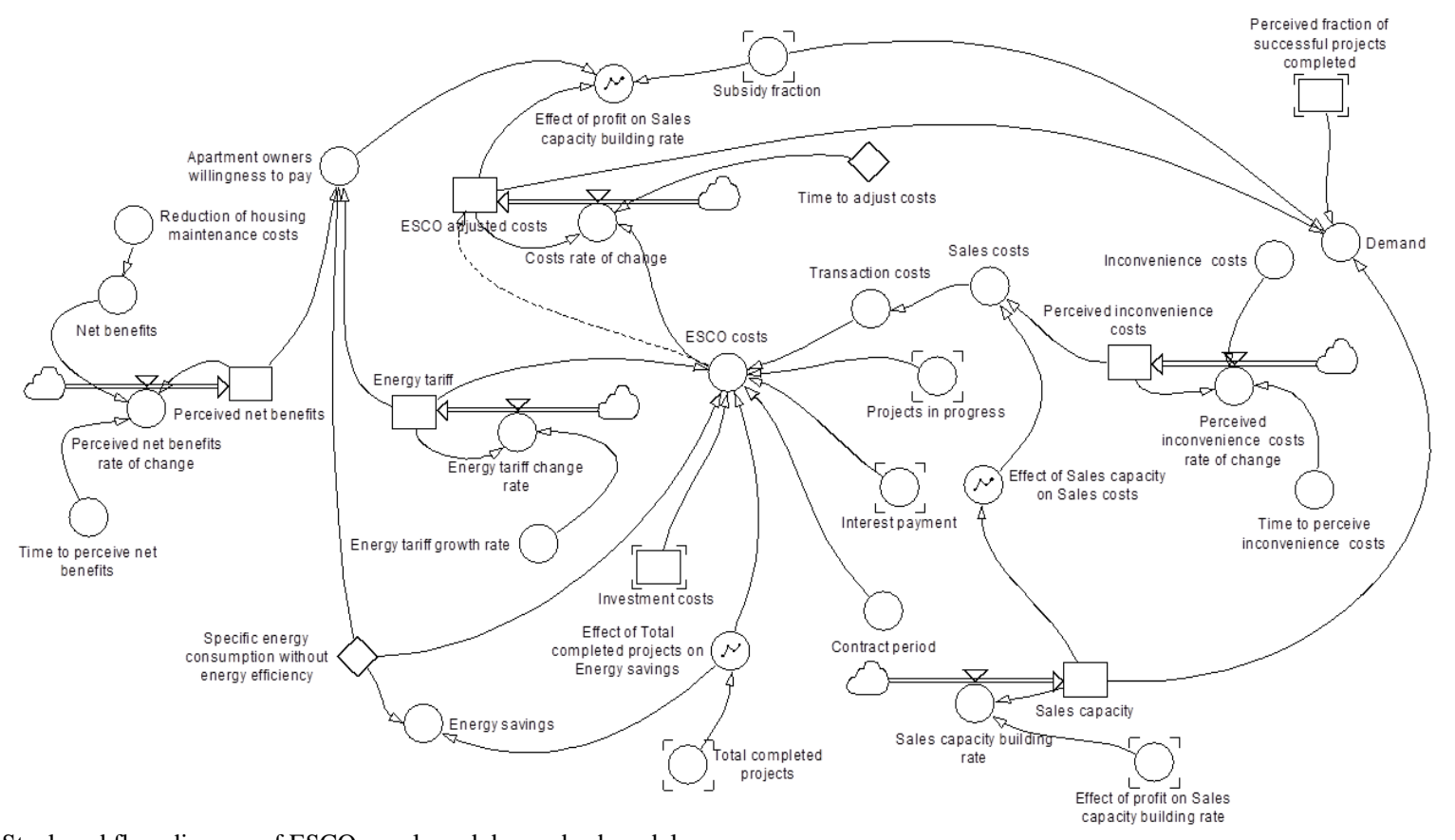

Fig. 4. Stock and flow diagram of ESCO supply and demand submodel. 


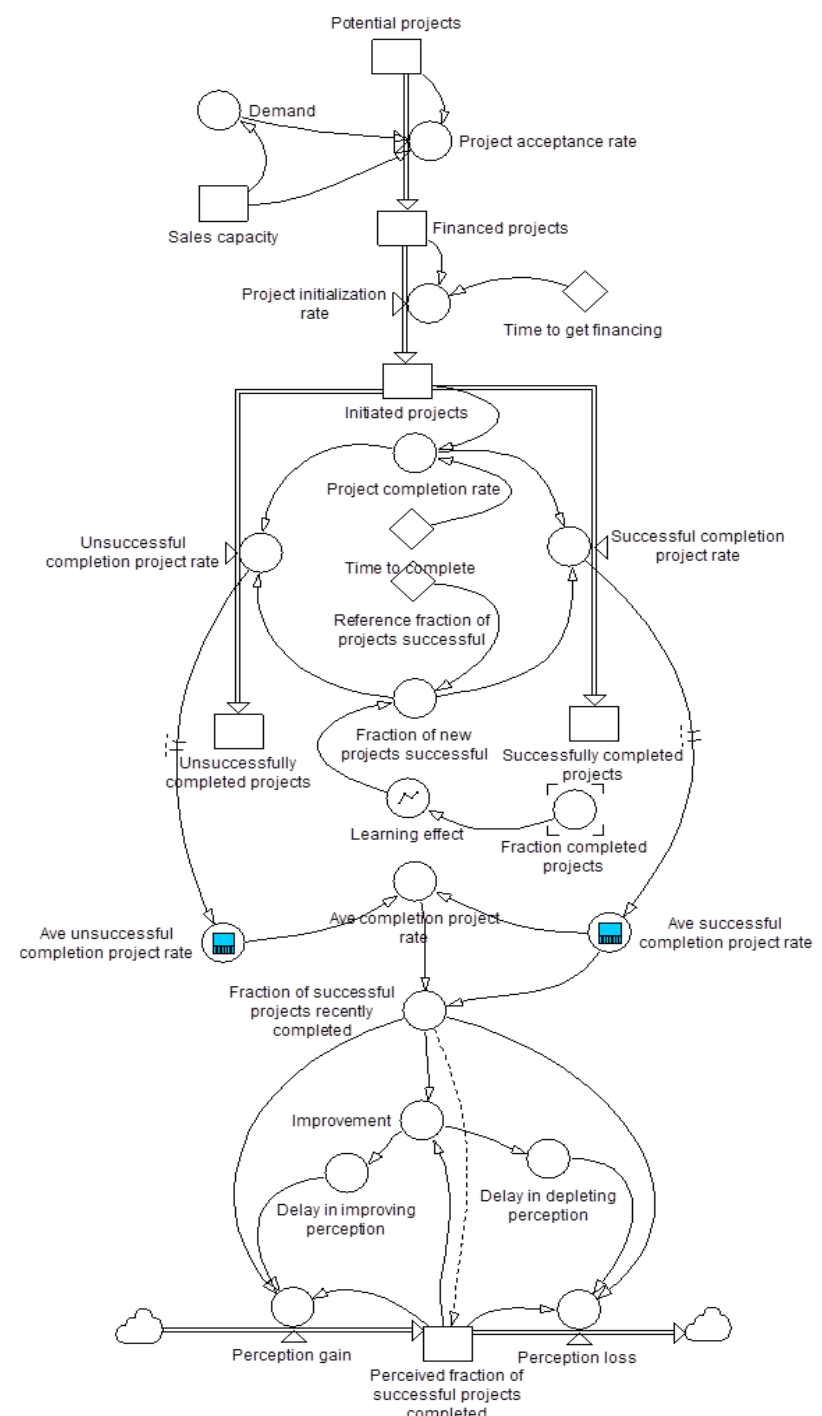

Fig. 5. Stock and flow diagram of building stock sub-model

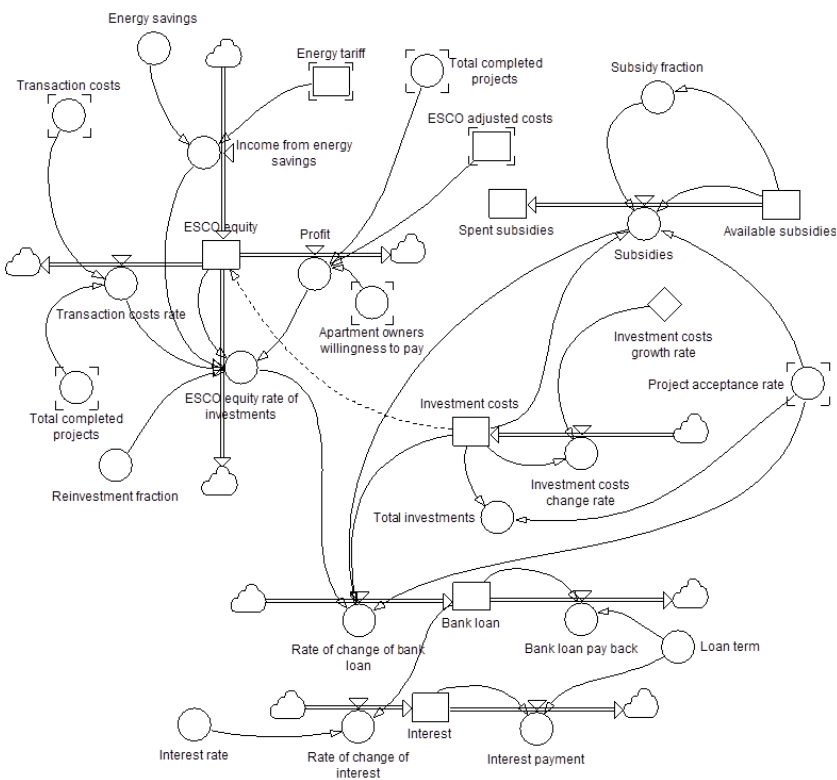

Fig. 6. Stock and flow diagram of financial sources submodel.

\section{MODEL TESTING AND VALIDATION}

Data quality and availability are always key concerns for all modelling exercises. Barlas [17] provides an
The building stock sub-model displayed in Fig. 5. is disaggregated into several stocks based on the main milestones of the energy efficiency projects. These include potential projects or buildings without energy efficiency measures, ESCO selected projects to be financed, ESCO initiated projects or buildings where the ESCO has signed contracts and both unsuccessfully and successfully implemented projects. Projects are measured in heated area $\left(\mathrm{m}^{2}\right)$. The rate at which buildings move from one stock to another is determined by factors influencing the rate. For example, project acceptance rate depend on demand and capacity; financing rates depend on the time needed to secure financing. The information available and acquired by apartment owners about ESCO projects implemented forms an important reinforcing feedback loop that determines demand. The higher the number of successful projects, the higher the demand for ESCO services and vice versa. The non-linear relationship of learning effect determines how the ESCO improves its performance over the time.

Fig. 6 illustrates the financial resources available to an ESCO dealing with the residential sector. Financing is provided by the subsidy program, the ESCO's own resources and the bank loan. The subsidy program has limited resources. The amount of the subsidy depends on the subsidy fraction and the project acceptance rate. The ESCO's equity is generated by energy savings from the implemented projects. This money is spent on the ESCO's operating costs. Any profit and any money remaining are reinvested in new projects. The bank loan is used if the project cash flow needs additional resources besides the subsidies and the ESCO's own financial sources.

Energy savings and GHG emissions sub-model is used to account for total energy savings at the national level as well as the reduction of GHG emissions. 
validation is performed before behaviour validation. In this study, model structure verification tests were carried out to assess both the structure and the components of the model. These tests included a structure assessment test, a parameter assessment test, a boundary adequacy test and a unit consistency test. This was followed by two behaviour tests: an extreme condition test and a behaviour sensitivity test. The extreme condition test measured extreme values of selected model parameters to compare the behaviour generated by the model with the anticipated behaviour of the real system under this value. The behaviour sensitivity test was used to determine the parameters on which the model is highly sensitive. These were compared with the sensitivity of the real system to these parameters. The tests showed that the most sensitive parameters are energy tariff, contract period, investment costs, specific energy consumption and the reference fraction of successful projects.

As an example to illustrate model validation, the behaviour sensitivity test, which tests the sensitivity of the total investment to the contract period, was performed. The initial value is set at 20 years. In each run, the contract period is increased or decreased by one year. When the contract period is increased, it has no impact on the total investment. The trend is very different if the contract period is decreased. Fig. 7. illustrates that as the contract period decreases below 15.4 years, the ESCO stops its investments for a certain period of time. This gap is needed for the ESCO to accumulate money from savings in the implemented projects. The shorter the contract period, the longer the time needed to accumulate financial resources.

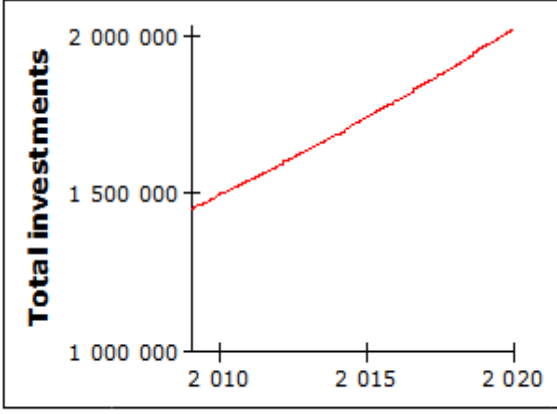

20 years

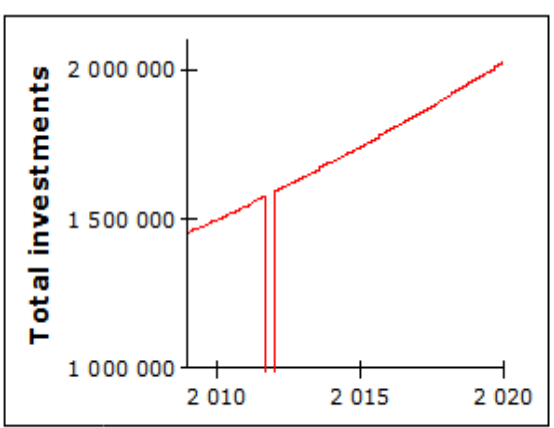

15.4 years

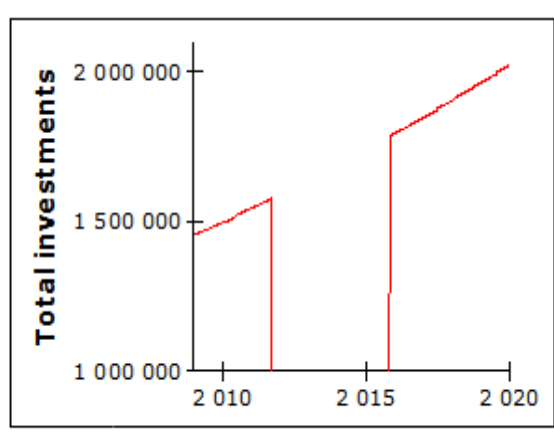

15 years

Fig. 7. Behaviour sensitivity test of total investments to contract period

Calibration and validation of system dynamics models can be performed using data from field collection and from the literature. Models which perfectly represent a system do not exist and simulated data generate only trends instead of accurate numbers. The historical behaviour validation test is used to build confidence in the model [18]. The simulated total number of projects in progress is compared with the historical data. The results are shown in Fig. 8. The trend of both the projects in progress (projects in progress added to completed projects) and the completed projects from model simulation match the historical data.

The first ESCO project in this sector was implemented and financed in 2009 by a subsidy program called, "Improvement of energy performance of multi apartment buildings". There is a time delay caused by the introduction of the ESCO concept to market. Data analysis shows the ESCO growth fraction increasing.

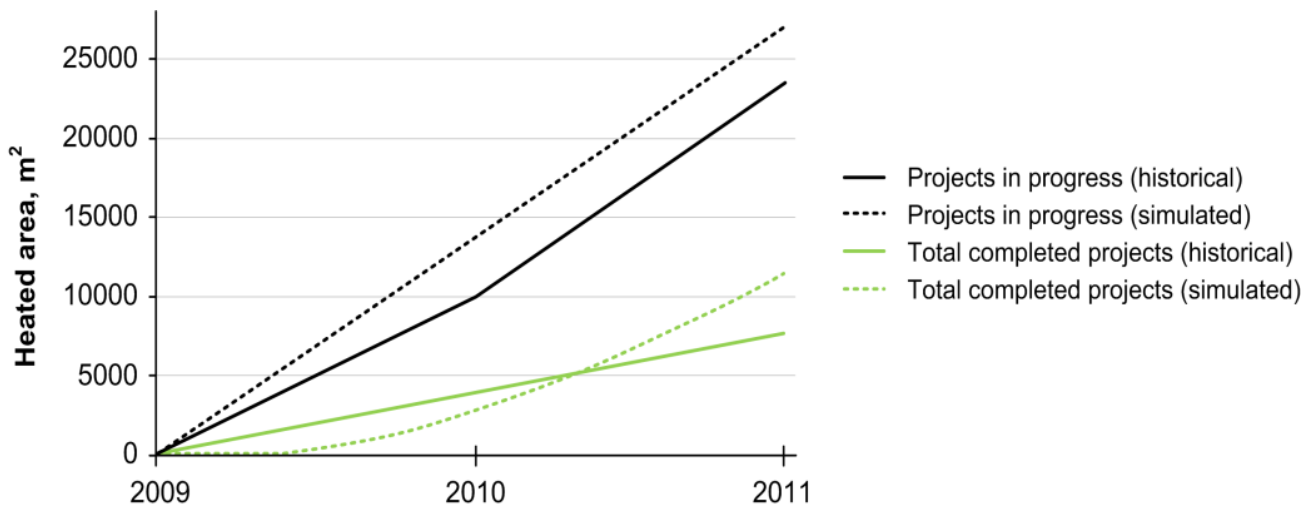

Fig. 8. Historical and simulated data of accumulated ESCO projects in progress and total completed projects

\section{REFERENCE BEHAVIOUR OF THE MODEL}

The reference behaviour of the model can serve as a basis for comparison of alternative policy tools. In this study, the main parameters characterizing the ESCO market in the residential sector are the total area of completed projects and the total area of projects in progress. In addition to these, the distribution of financial resources is reviewed. The time horizon used in the model is from 2009 to 2020 .

Fig. 9. shows the reference behaviour of both projects in progress and total completed projects. The number of implemented projects lags behind the number of projects in progress. The main reason for this is the 
delay caused by the time required to secure financing and the time required for the construction work.

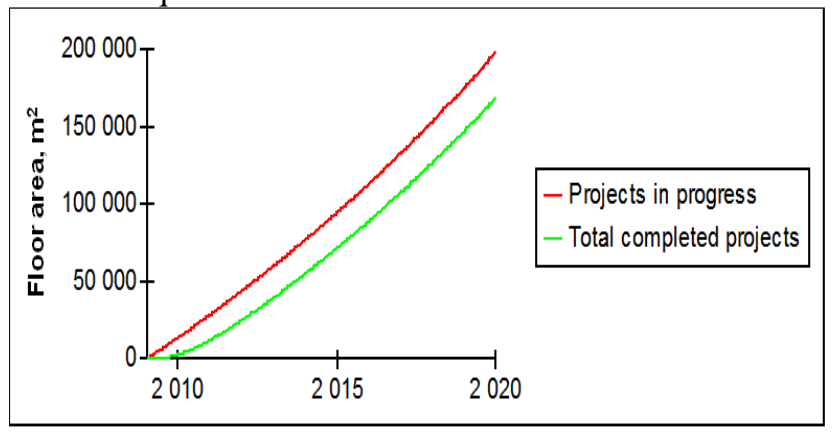

Fig. 9. Reference behaviour of projects in progress and total completed projects.

\section{ALTERNATIVE SCENARIOS AND POLICY TOOLS}

One of the goals of the system dynamics model is to test different policy tools that can be used to improve the performance of the system under study. Sorell [3] lists policy measures that may encourage ESCO market development. Only reinforcing information by publicfunded information programmes and demonstrations is relevant if the market is not well balanced as it is with a seller's market as in the case of Latvia.

RENESCO proposes additional policy tools that governments should use to reinforce the ESCO market diffusion. These are: (1) reduce the number of votes needed to decide whether to sign ESCO contract (now $51 \%$ of apartment owners have to agree); (2) real estate tax reduction for buildings that have contracts with an ESCO [15]; and (3) publicly finance information campaigns. In this study, all three policy tools proposed by RENESCO are modelled and simulated.

The proposed policy tools require either structural changes in the model or strengthening the endogenous feedback loops. If the number of votes required to sign ESCO contract is reduced, the inconvenience costs incurred by apartment owners are decreased, those reducing ESCO transaction costs. Simulation is performed with the value of inconvenience costs set at 0 .

A reduction of real estate taxes together with reduction of housing maintenance costs increases the net benefit of every apartment owner. This, in turn, increases the willingness of the apartment owners to pay and makes the ESCO more attractive to them. The structure of this policy tool is illustrated in Fig. 10. The value of reduction of real estate tax is set at $0.14 \mathrm{EUR} / \mathrm{m}^{2}$ per year.

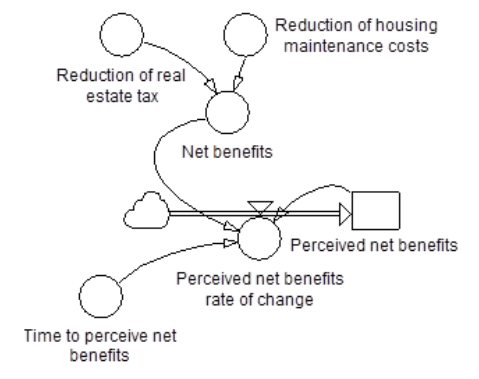

Fig. 10. Impact on ESCO market of real estate tax and reduction of housing maintenance cost reduction.

The last policy tool evaluated within this model is the information campaign. It can be used to begin and encourage the recruitment process (making people aware) and is measured as annual floor area of recruited buildings per year. It determines ESCO sales capacity building rate (see Fig. 11.). The information campaign helps to boost demand for ESCO services.

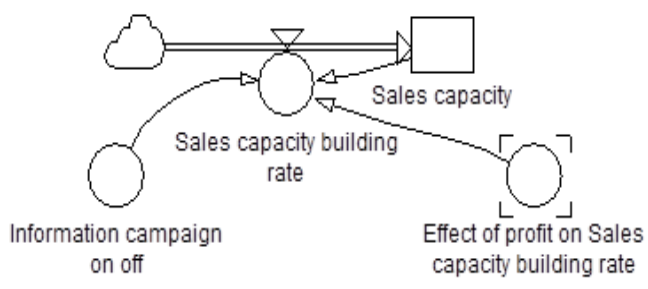

Fig. 11. Information campaign in the model.

\section{RESULTS}

Analysis of how the three policy options referenced above impact the ESCO market were simulated and compared with the reference behaviour.

If reduction of real estate tax is used as policy tool, the behaviour of both the projects in progress and the total completed projects follow the same increasing trend as the reference behaviour, but reached a higher number by 2020: 199,773 $\mathrm{m}^{2}$ compared with 198,048 $\mathrm{m}^{2}$. The increase is not significant. Number of votes needed for ESCO agreement (represented in model as inconvenience costs) does not impact number of implemented projects. The key to explaining the effect of both policy tools lies in the scale of both values - they form a very small part of total ESCO costs. These results do not confirm the assumption that the reduction of number of votes and the increase of net benefits is an effective set of policy tools to speed up the diffusion of ESCO services in the residential sector.

Fig. 12. illustrates the behaviour of both the projects in progress and the total completed projects if information campaign with three different levels of strength is used. In this simulation, the trend of behaviour in all three cases has not changed while the scale has changed noticeably. For example, if information campaign is not strong (500 $\mathrm{m}^{2} /$ year/year) compared with the reference behaviour, by the year 2020 the number of total completed projects increases to $230,673 \mathrm{~m}^{2}$ compared with $198,048 \mathrm{~m}^{2}$ in the reference behaviour. The financial resources show a similar trend of distribution compared with the reference behaviour. These results confirm the assumption that an information campaign is a highly effective policy tool to reinforce the diffusion of ESCO services in the residential sector. 


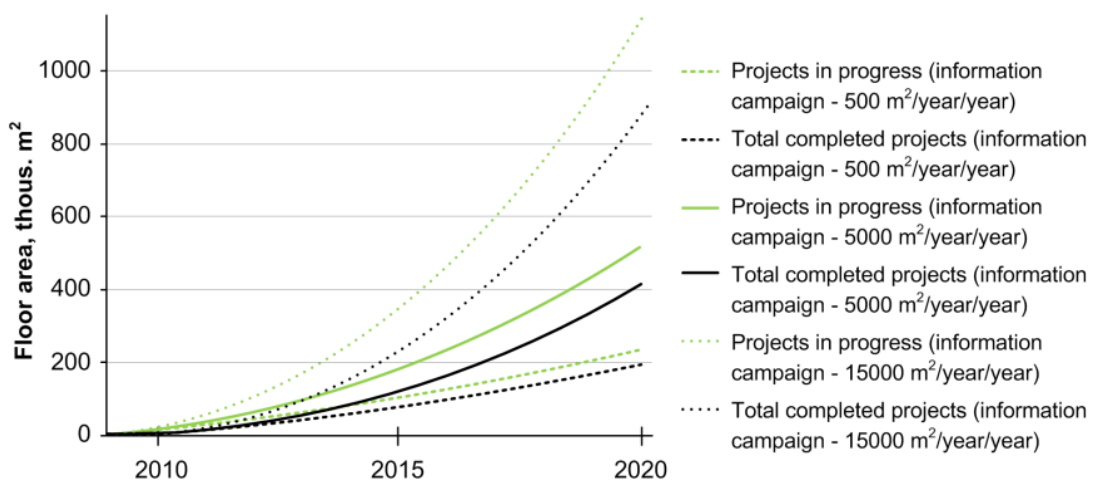

Fig. 12. Simulation results of information campaign.

\section{DISCUSSIONS}

The simulation results reveal that in the case of a suppliers' market, supply by an ESCO depends on the company's capacity, the investment costs, the ESCO transaction costs, the energy tariff, the available funding, the available information, and the net benefits. The critical factors affecting the diffusion of ESCO services are the length of the contract period, the initial values and any increases in energy tariff and investment costs.

The model places emphasis on relationships rather than on the exact numbers, especially in the case of the proposed policy tools. They have to be interpreted in an open-ended way since they may not represent what might or might not happen in the real world. The model simulation results show the strength of endogenous feedback loops within the system, and reveal the need for structural changes and integrated policy measures to obtain the highest diffusion rate of ESCO services in the residential market.

Given the present model structure, including currently available policy tools, it is possible to simulate the future development of the ESCO market. All parameters are based on information supplied by RENESCO, except for uncertainty costs. Although the system is not sensitive to this parameter, it gives some level of certainty to the simulation results.

\section{CONCLUSION}

In this study, system dynamics modelling was used to develop a model to simulate ESCO services in the residential market. The main feature of the system dynamics modelling is that the structure of the system is transparent, hence uncertainties with regards to future changes are more easily addressed. The model structure with its feedbacks, delays and non-linear relationships helps to understand the supply and demand of ESCO services as a system rather than an isolated set of variables. Information provided by RENESCO and microeconomics theory served as the basis for the structure of the model. While the literature sources suggest several policy tools to reinforce ESCO activities in the market, only three are proposed to be used in Latvia's residential sector - (1) reduction of real estate tax; (2) changes in voting structure of apartment owners, and (3) publicly financed information campaigns. Simulation results confirm that increase of net benefits reinforced by information campaign is highly relevant set of policy tools, however, removal of apartment owners' barriers do not reinforce diffusion of ESCO services in the residential sector.

\section{REFERENCES}

[1] A Roadmap for moving to a competitive low carbon economy in 2050, COM/2011/0112 final, Brussels, 2011.

[2] Directive 2006/32/EC Of The European Parliament And Of The Council of 5 April 2006 on energy end-use efficiency and energy services and repealing Council Directive 93/76/EEC, 2006.

[3] S. Sorrell, The economics of energy service contracts, Energy Policy 35 (2007) 507-521.

[4] C.A. Goldman, N.C. Hopper, J.G. Osborn, Review of US ESCO industry market trends: an empirical analysis of project data, Energy Policy, 33 (2005) 387-405.

[5] E. Vine, An international survey of the energy service company industry, Energy Policy 33 (2005) 691-704.

[6] P. Bertoldi, S. Rezessy, Energy service companies in Europe, Status Report 2005, European Commission DG Joint Research Centre, Ispra, Italy, 2005.

[7] P. Bertoldi, S. Rezessy, E. Vine, Energy service companies in European countries: current status and a strategy to foster their development, Energy Policy 34 (2006) 1818-1832.

[8] P. Bertoldi, S. Rezessy, B. Boza-Kiss, Latest Development of Energy Service Companies across Europe, Institute Environment and Sustainability, European Commission DG Joint Research Centre, Ispra, Italy, 2007.

[9] A. Marino, P. Bertoldi, S. Rezessy, Energy Service Companies Market in Europe, Status Report 2010, European Commission DG Joint Research Centre, Ispra, Italy, 2010.

[10] C. Capelo, Modeling the Diffusion of Energy Performance Contracting, 29-th International System Dynamics Conference in Washington, DC, 2011.

[11] Latvian Energy in Figures, Ministry of Economics of Republic of Latvia, Riga, Latvia, 2011.

[12] Data from Central Statistical Bureau of Latvia, database available at www.csb.gov.lv.

[13] Latvia's First National Energy Efficiency Action Plan of Latvia 2008-2011, Cabinet of Ministers of Republic of Latvia No.266, Riga, Latvia, 2008.

[14] T. A. Kõiv, A. Hamburg, M. Thalfeldt, J. Fadejev, Indoor Climate of an Unheated Apartment and its Impact on the Heat Consumption of Adjacent Apartments, 3rd International conference on Urban Sustainability, Cultural Sustainability, Green Development, Green Structures and Clean Cars (USCUDAR '12), Barcelona, October 17-19, 2012, 52-58.

[15] Conference ESCO Europe 2012, January 25-26, London, 2012.

[16] V. Oikonomou, F. Becchis, L. Steg, D. Russolillo, Energy saving and energy efficiency concepts for policy making, Energy Policy 37 (2009) 4787-4796.

[17] Y. Barlas, Formal aspects of model validity and validation in system dynamics, System Dynamics Review 12 (1996) 183210.

[18] J.A.M. Vennix, Group Model Building: Facilitating Team Learning Using System Dynamics, John Wiley and Sons, Chichester, 1996.

[19] A.Blumberga, G. Žogla, G., P. Davidsen, E. Moxnes, Residential Energy Efficiency Policy in Latvia, Proceedings of the 29th International Conference of System Dynamics Society, Washington, USA (2011) 35-36.

\section{Creative Commons Attribution License 4.0 (Attribution 4.0 International, CC BY 4.0)}

This article is published under the terms of the Creative Commons Attribution License 4.0

https://creativecommons.org/licenses/by/4.0/deed.en_US 